\title{
ISSUES AND PERSPECTIVES OF CAPACITY DEVELOPMENT IN EMBODIED ENERGY INDICES FOR BUILDING MATERIALS SOURCED IN NIGERIA: A REVIEW
}

\author{
S. C. Nwanya ${ }^{1, *}$ and H. N. Ononiwu ${ }^{2}$ \\ 1, 2, Department of MeChanical Engineering, UniVersity of Nigeria, NsuKKA, ENUGu State, NIGERIA \\ Email addresses: ${ }^{1}$ stephen.nwanya@unn.edu.ng, ${ }^{2}$ ndudim.ononiwu@unn.edu.ng
}

\begin{abstract}
Embodied energy (EE) property of building material is a great determinant of the performance of a building. The dearth of information on EE of locally sourced building materials (LSBMs) constitutes a challenge to affordable housing in Nigeria. In this paper, a review of the previous literature, unfilled gaps in those works, and future directions in embodied energy research for LSBMs is presented to evolve a Nigerian perspective. A constructive non-meta analytic methodology was adopted for the paper. This was followed by classification and comparison of snapshot literature in the embodied energy of building materials. Insightful sources of information for the study were drawn from a vast body of knowledge both documented literature and some interviews with knowledgeable personnel in the area of a built environment. From the survey, energy management opportunities were revealed, which would not have been apparent from a specific building case study alone. There are distinctions in the literature with this current paper for a Nigerian case study: none have addressed the embodied energy coefficient of materials. Also, the status of embodied energy studies, for these materials, is at a low profile and the few investigations carried out focused on life cycle operating energy of buildings. These research gaps evidently imply abundant research opportunities that await exploitation in the building industry. This paper adds to an existing body of knowledge on the use of EE index to promote and optimize the selection of LSBMs as alternative to imported building materials. We hope engineers, estate developers and architects would find it useful for making an informed decision in the design of resilient buildings using indigenous materials.
\end{abstract}

Keywords: building material, embodied energy, system boundary, capacity, building information modelling, Nigeria.

\section{INTRODUCTION}

As society advances, energy accounting for a production activity increases in importance. In production of goods and services including building materials, the energy consumed in the process is an indirect energy requirement [1]. This energy is known as an embodied energy (EE). It is an energy incorporated or embodied in the process rather than being an intrinsic property of the goods and services produced. EE is a topical subject matter in building information modelling systems (BIM) because of the role it plays in the design of a building and selection of building materials for construction. What are the benefits likely to accrue from the integration of EE in BIMs? This will provide a new frontier of knowledge for future efficient building design and complement the development of energy code for the Nigerian building industry. It will make the choice of less energy-intensive materials attractive and cost-effective. The overall contribution to the industry is the development of an information databank of LSBMs.

An overview of the existing literature on embodied energy has shown and confirmed the growing level 
of consideration attached to $\mathrm{EE}$ in more energyconscious construction [2]. Thus, the EE property of a building material is seriously a trending interdisciplinary research subject among professionals including architects, engineers, planners and builders due to its ability to influence the performance efficiency of a building. Among these professionals, however, there has been a considerable lack of uniformity of terminology, especially the definition used in the field of embodied energy and this has led to misunderstanding. Consequently, the exact meaning of this term is not always clear, and not always agreed upon among relevant professionals. For clarity, it is necessary at this stage that answers are provided to the following pertinent questions: what is embodied energy and why do we care? Doing that will elucidate interpretations ascribed to embodied energy as a concept.

\subsection{Definition of Embodied Energy of building material}

In the literature, [3- 6] state: embodied energy (EE) is the total primary energy consumed in all the processes of the production of a building material or building itself, which is accounted for within boundaries such as cradle-to-gate or cradle-to-site and cradle-to-grave, respectively. The sum of the energy expenditure due to building material production in any of those boundaries refers to embodied energy. The above definition has been contested against by some experts, who claim it is too encompassing, pointing out the vague process boundary limits as the major impediments to a consensus definition.

The perception of these authors concerning embodied energy differed from each other. The difference among them range from the principles, material extraction method to the goals of the subject matter. For example, in the light of material gathering processes, [7-8] maintain that the total energy sequestered in all products and processes used in constructing a building is called embodied energy. But, [9] consider embodied energy as the latent energy of a building associated with the materials in use for construction, construction process and maintenance. For a built environment, the embodied energy is comprised of energy of the material and actual building operations (operational energy). The contemporary authors seem to differ on the characterization of the boundary scope that should be associated with embodied energy. However, there is commonality across the studies. They are in agreement that EE is an energy accounting method and the demand for it is a process activity-driven demand.

There are various processes and phases linked to the building material mining and actual building assembling. At each of these processes and phases either for the material or building itself, energy is consumed. But, from the vast literature consulted the volume of energy requirements at each phase has been infrequently studied. So, embodied energy assessment for buildings is incomplete without reference to type and number of materials used in construction, the process of construction and operational (or proposed) activities within the building. These issues that little is known about require further research. To take into account the divergence of opinions concerning definition of embodied energy, this study has articulated embodied energy as the prime potential of a material which determines its performance efficiency in the operational function of a building. We account for EE in order to take advantage of four attributes of a building material. Three of the attributes according to Bullard and Roberts [10] include (a) Energy conservation: strike a balance between input and output resources based on first law of thermodynamics, (b) Energy efficiency: improve potential to save energy through the use of efficient materials or substitution of materials with more efficient ones; and (c) Cost savings: cost of a product correlates with the amount of energy consumed in its production and this has proven to be a strong and positive correlation. The advocacy is to maintain a low, but positive correlation. The fourth attribute is Eco-friendliness, which supports the assertion by [11] that material EE property is a critical issue in describing green building. Although, the importance of those attributes have been highlighted in greater detail in several studies, there are divergent gray areas which should be stressed. To this end, we believe the strength of the current study lies in some lucid exposure of the subject area from the perspective of capacity development in EE. Doing that will lead to a pull of skills for the building sector in Nigeria. To the best knowledge of the authors, the extant literature on building materials in Nigeria does not cover this exposure on indigenous materials. 
In the light of foregoing argument, this paper aims to underscore the practice and understanding of the $\mathrm{EE}$, especially for the LSBMs. The specific objective is to evaluate the literature on indigenous building materials and expose the current state of research in the area, identify gaps in the research topics and future directions. The research interest in local materials is of the essence because Nigeria is endowed with an abundant number of them, both renewable and nonrenewable, with potential for commercial exploitation in the construction industry. But presently, their commercialization is limited by lack of standardized energy code building material information data base. Apart from providing comparable data as a basis for adjudging how the indigenous materials are sustainable along with equivalent foreign ones, the determination of EE content ensures a way of mitigating climatic change effect due to buildings, since it can give a clue to carbon emission levels that result from using them. The novelty in this paper is the use of EE index to promote and optimize selection of LSBMs as alternative to imported building materials. The utmost likelihood that this information would be of general interest to all stakeholders in the building industry is certain.

The outline of this paper begins with an introduction in section 1 , while section 2 explains the procedure adopted for the review. This is followed by a need for inclusion of LSBMs in global building information database. The extent of EE studies in Nigeria is expressed in section 3. Barriers to implementation of embodied energy of local building materials in construction industry are discussed in section 4.

\section{RESEARCH METHODOLOGICAL APPROACHES EMPLOYED FOR EE STUDIES}

For the review of research on embodied energy in this paper, a qualitative review method of pertinent literature sources was adopted. This method was used for gathering reliable information from sources comprising academic, government policy documentary and industrial case studies. All the qualitative methods involve the search by web browsing and consultation of institutional as well as public libraries. Other available methods are the bibliometric analysis and case study. The bibliometric studies focus on using quantitative measures such as keyword co-occurrence and term co-occurrence to identify emerging trends and future research topics in a specific field [12]. But, case study is an ideal methodology when a holistic in-depth investigation is needed, according to [13] as cited by [14]. Unlike case study, the academic study provides insights into a number of variable factors that influence a subject matter. The criteria for selection of a local material was based on how frequent it was used for a construction activity at a building site. In the reviewed articles, methodology for embodied energy calculations was based on the well-known process analysis and includes the energy use associated with construction activities. On the actual evaluation of material $\mathrm{EE}$, the life cycle assessment (LCA) method is widely used to estimate the embodied energy [[2], [15]. LCA is suitable where a holistic evaluation of the total amount of energy associated with a component or entire extraction, manufacturing and transportation of a material is required. The industry reports, software, data sets, and standards were evaluated to shape the context of embodied energy calculation and reduction in practice. The $\mathrm{EE}$ coefficient is estimated by aggregating the energy consumed in producing material plus that for building construction itself and dividing that sum by aggregate weight of the materials. Computing embodied energy of materials is difficult and more complex than calculating operating energy due to the unavailability of quality data and a standard calculation method [16].

While the reviewed literatures tend to present similar procedure for calculation of embodied energy coefficient, the assessment of level of embodied energy consumption per building material type is skewed and inconclusive. Although, the building sector has been globally identified as the highest consumer of embodied energy, from 40 $\%$ to $60 \%$ [17-18], this level of energy consumption still vary according to the material and manufacturing process types. For example, on the average, for a ton of iron produced, the industry needs about 460 cubic meters of natural gas, about 59 kilograms of oil and about $1400 \mathrm{KWh}$ of electricity [19-20]. Even, among countries, there is variation in manufacturing technology due to bio-climatic principles [21] which affect the life cycle energy consumption of building materials. In terms of material type, however, there are high (such as steel) and low (such as wood) embodied energy materials. 
Both types complement each other in the construction of buildings at varying mix ratios. In the context of level of assessment, the argument posit is that low embodied energy materials are greater in number than the high embodied energy materials. If we align this counting approach to the popular $A B C$ inventory classification by value as applied in the basic principles of production control, the high EE materials should therefore, deserve priority attention. The $A B C$ inventory classification is a material value distribution approach where a small number of items, say 15 to $20 \%$, in a group will account for 70 to $80 \%$ of the bulk of the total value [22]. This concept is applicable to the indigenous materials. Since the class $A$ (high $\mathrm{EE}$ value), $B$ (medium EE), and C (low EE value) materials can be locally sourced, directing $E E$ research attention to the later classification will provide the advantage of reducing environmental impact of these materials in the construction industry. In addition, they are usually consumed in large quantities, whereas those materials with higher embodied energy content such as stainless steel are often used in much smaller amounts [21]. Generally, four essential steps are involved in computing the embodied energy. For example, in the case of a multi-story office building, the following steps, are outlined:(1) Select case study office buildings for analysis. (2) Determine embodied energy coefficients for building materials used in the case study buildings.(3) Analyse bills of materials for selected case study buildings by material and element. (4) Apply embodied energy coefficients to quantities of materials used in each element [23]. These steps are similar to a fourstage sequential qualitative approach for measuring embodied carbon dioxide equivalent of buildings [24]. For a summation, the embodied energy coefficients for the building materials were multiplied by the quantities derived for each of the case study buildings. The totals for each element were divided by the gross floor area (GFA) of each building to make the results comparable across the different buildings. Despite increasing in-depth attention being directed to embodied energy of buildings, the recent researches indicate that a vast country-wise new local input materials are possible. Similarly, there has been increased recognition of the significance of indigenous materials in Nigeria thereby promoting cost-effectiveness in the building sector. But these new indigenous materials require test to quantify their EE coefficient status.

\section{NEED FOR INCORPORATION OF INDIGENOUS NIGERIAN MATERIALS EE COEFFICIENTS IN THE GLOBAL BUILDING INDUSTRY DATABASE}

Affordable housing for all in Nigeria is real and achievable. But, how can it be accomplished without navigating through the inferior status of LSBMs? Some of the basic indigenous materials include cement, stone, bricks, bamboo and palm trunks, sand, grass and straw bales. Use of the materials in our building industry has been a long time practice. Over these periods, however, the traditional image of a local material as a cheap and transient object has dominated the market. In turn, the LSBMs have competed with imported materials on price, rather than on the basis of ecofriendliness. An aspect of the economicenvironmental attributes of the local building materials that is rarely investigated is how much their EE affects acoustic quality. Typical cases in hand in respect of the aforementioned acoustic property are the "Uruh" (Musanga cerropiodes) and "Nturupka" (pterocrpus erinaceus) wooden materials used in the construction of "talking" drums. Knowledge about acoustics is important because the acoustic quality of an indoor environment affects work performance and employee behaviour at work [25]. Next vital characteristic quality of the local materials is their EE coefficients to enable their utilization as well as facilitate comparison with other materials elsewhere in design calculations. Hence, an inventory of $\mathrm{EE}$ coefficients for the LSBMs needs to be investigated and determined.

The desirability of determining the EE coefficient of indigenous materials is critical to the quest for a database of sustainable material resources, particularly when we consider the growing demand in the society for green and smart buildings. The engineers, developers, quantity surveyors and architects need EE information for making informed comparative decisions on building design. In this manner, the EE coefficient provides a framework of action to overcome the inferiority status of the LSBMs among imported materials. A Nigerian content in terms of design database (such as $\mathrm{EE}$ indices) of the indigenous materials that would have been created out of building material supply chain 
will serve as a catalyst for job creation and capacity breeding in the building industry. The implications of building materials supply chain on the industry are enormous including economic diversification, engineering skill development and national security. From the economic diversification outlook, our indigenous materials are economically viable. Using them as replacement for imported materials adds to the value chain of and increases material mix for the building industry, leading to resource efficiency. Resource efficiency of a building material reduces waste in the manufacturing processes [26]. With that in place, it also means that EE capability enhances the engineering value of a material, thus making it available for wider application. On the part of national security, there will be reduction of capital flight and by implication conservation of foreign earnings. Also, if the materials are appropriately extracted, they will not affect food security. With these prospects the Nigerian content in EE research has a huge unexploited market for local materials.

Shelter is a basic human need and one of the fastest ways possible to satisfy it is to adapt reliable and cost-effective LSBMs. The indigenous materials cannot readily fill this gap because their technical performance indices with which to conduct a comparative appraisal with equivalent foreign materials are latent. Although most of those indigenous materials are used in traditional building, they are inherently presumed energy efficient. But, there are no verifiable scientific proofs in the database to substantiate this claim or measures that can lead to the choice of one material over another. In addition, the choice for them in building design was not based on the role their energy content plays in the building. It was rather on the basis of economics, but costeffectiveness alone is inadequate for reliability and quality assurances. While energy content of materials gives information about efficiency of performance, the cost system only provides data for the preparation of material budget, a planning tool for the industry. For the building industry to perform the role of facilitating affordable shelter with comfort, EE of LSBMs is an important database. With this information, planners, architects and engineers stand better chance to minimize energy content in building processes and also prevent environmental pollution [27] because of easy access to data.
In the preceding tasks for the promotion of LSBMs, the argument in their favour centers on availability as affirmed by [28], renewability [29], manufacturability [30], eco-friendly characteristics and low cost or economics of usage [31]. But, these factors are insufficient without EE characterization as a measure for a legal acceptability in a comparative analysis with imported materials. Other technical problems linked to this include durability [32], rate of energy interchange, energy accumulation capacity and thermal resistance. More research efforts are required in these perspectives. Presently, the volume of work carried out to address those research deficiencies involving local materials is insufficient. The paucity of research work creates the necessity for stepping up EE research in construction industry in Nigeria. Even, the results of literature search showed that the few works done so far were skewed towards operating embodied energy as evident in the proceeding sub theme.

\section{THE CURRENT STATE OF RESEARCH WORKS CARRIED IN THE SUBJECT AREA}

Ezema et al., [9] estimated embodied energy in residential buildings in a Nigerian context. The study therefore applied the whole life cycle assessment approach to embodied energy of residential buildings in Nigeria's most industrialized city of Lagos. It is similar to the work by [33] who conducted the embodied energy analysis of multi storied residential buildings in urban India, although the climatic conditions differed. Abanda et al., [6] conducted an embodied energy and $\mathrm{CO}_{2}$ analyses of mud-brick and cement-block houses in order to improve their use in construction as well as energy efficiency. Ononiwu and Nwanya [34] estimated the embodied energy and carbon dioxide emissions of a one storey building in eastern Nigeria. This is an extension to the standard EE of residential building assessment that captures carbon footprint. The authors applied the bills of engineering measurement and evaluation (BEME) of the case study building, which contains the unit measurement of each material used in the building construction. Then, the sum of these weight measurements was used to divide energy consumed in producing the building and the result obtained is the embodied energy for that building. This study also shows that concrete mixture has highest value of embodied energy while embodied carbon is directly correlated with embodied energy. 
Prucnal-Ogunsote [35] classified Nigerian architecture into the north and south models based on materials used in them. Results obtained show that traditional construction materials like rammed earth or clay and thatch roof is more energy efficient than most of the materials commonly used in Nigeria today. Oladiran [36] investigated the utilization of local building materials in Nigeria. Ede et al, [37] appraised the use of timber as structural members for residential buildings. A demonstration of how building envelope responds to outdoor conditions has been carried out using some selected LSBMs from Ile-Ife Nigeria [38].

In the area of embodied energy evaluation tools and decision support systems, the application of building information modelling is at a low ebb in Nigeria. Building information modeling (BIM) is a digital representation of physical and functional characteristics of a building facility. Prior to BIM, real-time monitoring of a building behaviour was manually conducted. As a set of interacting processes, BIM methodology has minimized human involvement in building life cycle management [39]. Autodesk EcotectTM is a BIM environmental simulation tool that can be used for analysis of thermal loads, lighting design, shadows and reflections, shading devices, and solar radiation [40]. BIM is useful for making critical decisions since it avails the designer different orientations of the building. In [6] Revit, a BIM tool, was used to validate the manual computational results. Despite the few validations on the existing structures, there is limited application of parametric approaches (simulation) to investigate how different material characteristics affect the results of embodied energy values.

In a summary, there is currently an insufficient literature on the embodied energy coefficients of locally available building materials as shown in Table 1. The shadow picture from Table 1 fits into the opinion by experts that the building industry in Nigeria is characterized by a high component of imported materials. The implication on the industry is the inability to meet housing needs. However, some experts attribute this problem to randomized change in foreign exchange rate and high dependence on imported materials. Notwithstanding these limiting factors, quantifying the embodied energy values for indigenous materials can provide key insight into the design of low-carbon buildings and the gateway to further surmount the myth of inferiority of LSBMs among imported materials.

\section{BARRIERS TO IMPLEMENTATION OF AN EE OF LOCAL BUILDING MATERIALS IN CONSTRUCTION INDUSTRY}

The low use of Nigerian indigenous materials in construction works has been observed. Although the non-characterization of their embodied energy coefficients in BIM systems is blamed for this low domestication, it is only a consequence of some fundamental factors yet be addressed.

Table 1: Level of research on embodied energy for building material and buildings in Nigeria (own studies)

\begin{tabular}{ll}
\hline Author (s) & Title \\
\hline $\begin{array}{l}\text { Ononiwu and } \\
\text { Nwanya [36] }\end{array}$ & Materials for Building Construction.
\end{tabular}
Aim \& Objectives

Nwanya [36] Materials for Building Construction.

This research therefore aims at investigating the

Ezema and Olotuah [9]

Estimating Embodied Energy in Residential Buildings in a Nigerian Context.

Organizational Factors Affecting the

Abisuga and Usage of Sustainable Building Oyekanmi [41] Materials in the Nigerian Construction Industry

Onyegiri and Ugochukwu [42]
Traditional building materials as a sustainable resource material for low cost housing in Nigeria: advantages, challenges and the way forward. utilization of local building materials in Nigeria.

This study applied the whole life cycle assessment approach to embodied energy of residential buildings in Nigeria's most industrialised city of Lagos

Identified the organizational factors affecting the use of sustainable building materials in the Nigerian construction industry from the perception of the contractors and professionals

The paper appraises some major local building material available in Nigeria examine the major advantages, challenges and the way forward for traditional building materials in increasing low cost housing supply and affordability in Nigeria 


\begin{tabular}{lll}
\hline Author (s) & Title & Aim \& Objectives \\
\hline $\begin{array}{l}\text { Nwanya and } \\
\text { Ononiwu [34] }\end{array}$ & $\begin{array}{l}\text { Embodied Energy and Carbon } \\
\text { footprints in Residential buildings. }\end{array}$ & $\begin{array}{l}\text { The work estimated the embodied energy and carbon } \\
\text { dioxide emissions of a one storey building in eastern } \\
\text { Nigeria }\end{array}$ \\
$\begin{array}{l}\text { Obia, et al } \\
\text { [43] }\end{array}$ & $\begin{array}{l}\text { Sustainable Architecture: Bamboo in } \\
\text { in South-South Nigeria. }\end{array}$ & $\begin{array}{l}\text { Investigates the use of bamboo as props for form } \\
\text { works. }\end{array}$ \\
$\begin{array}{l}\text { Ameh, et al } \\
\text { A44] }\end{array}$ & $\begin{array}{l}\text { Acceptability and use of innovative } \\
\text { of residential buildings in Nigeria. }\end{array}$ & $\begin{array}{l}\text { Explores use of innovative bamboo products for } \\
\text { residential building construction. }\end{array}$ \\
\hline
\end{tabular}

Embodied energy value can differ for different countries, sometimes by as much as $100 \%$, depending on a number of factors such as type of manufacturing processes, recycling technologies, methodology of analysis, fuel costs and destination [45] as well as material type (specie). Furthermore, the contribution of micro climatic condition, as one of the fundamental factors, to the variability of the LSBMs embodied energy values is yet to be investigated. In the work by [46], it is evident that energy code was omitted in the general codes for Nigerian based wood on the strength of impact of micro climate on EE of the materials.

So far, [41] only identified the organizational factors affecting the use of sustainable building materials in the Nigerian construction industry from the perception of the stakeholders such as contractors and professionals. According to this study, the factors include: lack of awareness on the part of construction personnel; organizational goal and objectives (interest) for the contractors; cost and economic viability which are significant internal factors. On the other hand, research and development, knowledge and skill of personnel are treated as external factors. These factors are inextricably linked to the prevailing level of development in a country. Since operational energy of buildings can vary from region to region, the level of development in each region also can be a veritable factor which affects the discrimination of indigenous material more than embodied energy deficiency.

Also, the conflict of culture due to colonial orientation posed a subtle factor that influences use of indigenous building materials. Prior to the colonial era, rural housing decoration depicts the cultural identity of a people or community setting. Then, these rural houses were built out of the ingenuity and available resources in the community. But, these ingenious skills gave way to modern architecture at the advent of colonial era. Modern architecture brought with it a change in housing design modelled after the expatriate's taste and built using imported materials. The important factor about this practice is that, the local materials which should have been appreciated were ignored and classified as unfit at the expense of imported products [47].

Onyegiri and Ugochukwu [42] appraised some major local building materials available in Nigeria with respect to their major advantages, challenges and future outlook usage in increasing low cost housing supply and affordability in Nigeria. The work strongly recommends the adoption and improvement of the locally available building materials for building construction in Nigeria. He also observed that emergence of mega-cities indirectly made huge demand on embodied energy of materials. The implications, according to [48] concern deforestation, high cost of building and intensification of emissions pollution. For example, mega-cities depend on the environment for energy, industry, construction, infrastructure and maintenance. Generally, all the processes of the building material extraction, transportation and usage result in one form of environmental impact or the other. None of these reports has addressed the issue of suitable selection criteria for the indigenous materials and the EE index is an element of ISO 14000 series certification criterion. In the preceding mega city example, it is pertinent to point out that the operations of quarry and borrow pit sites constitute pollution sources. The resulting safety and health hazards at those sites are yet to be addressed and they therefore provide veritable issues for scientific inquiry.

The material supply chain or process choice can also influence embodied energy consumption, particularly the transportation embodied energy. Some authors have attempted to list some of the LSBMs, but more needs to be done in terms of their transportation characterization. For the LSBMs, 
there exists a wide variation in transportation charges, which do not reflect the distance the materials are moved from source/harvesting points to construction sites. This suggests that scheduling, handling, delivery or materials management charges of embodied transportation energy flow requires a professional for coordination and control as the materials move from sources through suppliers to site. Materials management means a coordination of the journey of LSBM; applying right skills and techniques to materials and ensuring they reach final customer at lowest cost, on time and as required. This blueprint for LSBM supply chain management will control the charging process and direct research efforts towards standardizing it, which is a task eminently necessary in Nigeria. These functions are as transportation is a major element of embodied energy of construction materials [49]. In the foregoing context, building materials have been categorized, based on manufacturing strategy and response to market demand, into make-to-stock (MTS), assemble-toorder (ATO), make-to-order (MTO), and engineerto-order (ETO) products [50]. Since these strategies have unique supply chain arrangements, from cradle- to- gate or cradle-to-service, the transportation embodied energy for each of them will also differ and hence requires harmonization.

Sustainability aspect is another cogent factor affecting use of indigenous building materials in Nigeria. Sustainable building materials should also satisfy the following criteria: rational use of natural resources; energy efficiency; elimination or reduction of generated waste; low toxicity; low embodied energy, renewability; water conservation; affordability [51 - 52] and ecoefficiency [53]. Sustainability criterion has been used in grouping building materials as follows: materials that reduce the use of resources; materials that minimize environmental impacts; materials that pose no or low human health risks; materials that assist with sustainable site design strategies; materials from companies with sustainable social, environmental and corporate policies. The more concentration of sustainable materials in a building, the more efficient is the building. Eco-efficiency seeks to simultaneously reduce costs and environmental impacts using tactics such as waste reuse and technological improvement [53]. The benefits of waste re-use were discussed in the paper by Jalam et al [54], who worked on building materials derived from agricultural waste. By using agricultural waste, according to them, the environment is free of pollution from the accumulation of these wastes as a significant benefit. The agricultural material holds out to cheap and affordable building construction and the vast arable land in Northern Nigeria provides the platform for such an opportunity. Baiden et al [55] emphasized the importance of savings on energy consumption and greenhouse gas emissions (eco-friendliness) as a key requirement of sustainable housing. For this reason, [56] noted for developing countries such as Nigeria, the real test of their housing policy still remains the provision of comfortable and affordable housing for the vulnerable group. Other characteristics of sustainability inherent local materials include availability (ease of use). In a summary, efficient housing is a fundamental need and indigenous materials are essential to stimulate it, but must be given priority by eliminating the aforementioned barriers. However, a key performance index for our indigenous building materials, the $\mathrm{EE}$ must be ascertained as an indispensable common denominator for the stimulation. It has become necessary because embodied energy can be used in more fields (identify the linkage effects of policies) and it can provide a new perspective for the study of energy-related issues [57]. Thus, it enables us to analyze energy-related issues from the perspective of the whole supply chain and the whole energy flow network, instead of based on single energy supply or a single stage of energy consumption [5859].

\section{CONCLUSIONS}

The issues and future directions of embodied energy research for building materials from Nigeria has been examined. The general finding from literature search is that embodied energy impact on building material tend to correlate positively with its volume, extraction method, distance moved, mode of travel, manufacturing strategy and end of service usage. Researchers of Nigerian extraction seem unconcerned or unaware of prospects and developments surrounding EE of building materials. Further in the literature, it has been shown that authors have focused attention on embodied energy impact relating to operation of buildings, thus neglecting that of material extraction, production and transportation. To the best 
knowledge of the authors, the extant literature on building materials in Nigeria does not cover EE coefficients for indigenous materials.

In this review, highlight of the problems of a lack of energy codes or indices as internationally comparable selection criteria for local building materials was exposed. Absence of these coefficients hinder the integration and application of local materials within the BIM system. Under such conditions, our local materials are treated as inferior to foreign materials since it is difficult to compare both with undisputed common criteria. Given that background and with support of the current study measures are suggested to close the identified gaps. The study reinforces the fact that the level of industrialization correlates with the level of industrial energy consumption and it affects energy content of manufactured goods. Other variations occur because of uncertainties associated with the computation method, technological differences (for example, different types of cement kiln require different quantities of energy) and different fuel mixes used in the process. Due to the economic, technical and ecological benefits of $\mathrm{EE}$, developing its capacity for national building materials is crucial for the envisaged cost-effective and reliable housing development.

\section{ACKNOWLEDGEMENT}

The authors wish to express their profound gratitude to the University of Nigeria Nsukka and TetFund for providing facility and funding assistance, respectively for this on-going study. Also, they express appreciation to the anonymous reviewers.

\section{FUNDING}

The research was funded by the TetFund (DESS/UNN/NSUKKA/RP/VOL.X), Nigeria.

\section{REFERENCES}

[1] Reinders, A. H. M. E., K. Vringer and K. Blok "The direct and indirect energy requirement of households in the European Union", Energy Policy 31: 2003, 139-153.

[2] Tarabieh, K., M Khorshed "Optimizing Evaluation Methods for the Embodied Energy and Carbon Management of Existing Buildings in Egypt", Buildings, 9, 90; 2019, pp2-16.

[3] Griffin, C.T., Reed, B., \& Hsu, S. "Comparing the embodied energy of structural systems in buildings", In: Cruz $\mathrm{P}$, editor. Structures and Architecture: Proceedings of the 1st International Conference on Structures \& Architecture (ICSA2010). Guimarães, Portugal, 21-23 July 2010. 1333-1339.

[4] Hammond, G. P., C. I. Jones ( 2008) Embodied energy and carbon in construction materials. Proceedings of the Institution of Civil Engineers - Energy, vol. 161, no. 2, 2008, pp. 87-98.

[5] Milne, G., C. Reardon Embodied Energy, 2008, pp136-139 www.ecospecifier.org accessed March 14, 2009.

[6] Abanda, F.H., G.E. Nkeng, J.H.M. Tah, E.N.F. Ohandja, M.B. Manjia "Embodied Energy and CO2 Analyses of Mud-brick and Cement-block Houses", AIMS Energy, Volume 2, Issue 1, 2014, 18-40.

[7] Dixit, M. K, .J. L. Fernandez-Solis, S. Lavy, C.H. Culp "Identification of parameters for embodied energy measurement: A literature review", Energy and Buildings, vol. 42, 2010, pp. 12381247, 2010.)

[8] Treloar, G., R. Fay, B. Ilozor, P. Love "Building Materials selection: greenhouse strategies for built facilities", Facilities Vol.19:, 2001a, pp. $139-49$.

[9] Ezema, I.C., A. O Olotuah, O. I. Fagbenle "Estimating Embodied Energy in Residential Buildings in a Nigerian Context", International Journal of Applied Engineering Research, Volume 10, Number 24, 2015, pp 44140-44149

[10]Bullard III, C. W., R. A. Roberts "Energy Costs of goods and services", Energy Policy, Vol. 3 (4), 1975, pp $268-279$.

[11] Chan, A. P. C., A. Darko, E. E. Ameyaw "Strategies for Promoting Green Building Technologies Adoption in the Construction Industry-An International Study", Sustainability 2017, 9, 969.

[12] Zeng, R., A. Chini "A review of research on embodied energy of buildings using bibliometric analysis", Energy and Buildings, 155, 2017, 172-184

[13] Feagin J., Orum A. and Sjoberg G. eds., A case for case study, University of North Carolina Press, USA, 1991.

[14] Langston Y. L., Langston C.A. "2008 Reliability of building embodied energy modelling: an analysis of 30 Melbourne case studies", Construction Management and Economics, 26(2), 2008, 147-160.

[15] Cabeza, L. F., C. Barreneche, L. Miró, J. M.Morera, E. Bartolí, A. L. Fernández "Low carbon and low embodied energy materials in buildings: A review", Renewable and 
Sustainable Energy Reviews 23, 2013, 536542.

[16] Praseeda, K. I., V. Reddy, B. V.; Mani, M. "Embodied and operational energy of urban residential buildings in India, Energy and Buildings 110: 2016, 211-219.

[17] Haynes, R. "Embodied energy calculations within life cycle analysis of residential buildings" Available at: <http://etoolglobal.com/>. accessed June12, 2019.

[18] Deshwal, A. (2011). "Using bamboo in housing and building construction." Available at:<http://pib.nic.in/>. accessed June 12, 2019.

[19] Sasi, J. M. B. "Air pollution caused by iron and steel plants", International Journal of Mining, Metallurgy \& Mechanical Engineering, 1(3), 2013, 219-222.

[20] Doushanov, D. "Control of pollution in the iron and steel industry." Pollution control technologies, 2015, 3.

[21] Sattary, S., D. Thorpe "Optimizing embodied energy of building construction through bioclimatic principles" In: Smith, S.D (Ed) Procs 28th Annual ARCOM Conference, 3-5 September 2012, Edinburgh, UK, Association of Researchers in Construction Management, 1401-1411.

[22] Plossl, G. W. (1985) Production and Inventory Control: Principles and Techniques. $2^{\text {nd }}$ Edition, Prentice Hall, New Jersey.

[23] Treloar, G.J., R. Fay, B. Ilozor, P.E.D. Love "An analysis of the embodied energy of office buildings by height" Facilities Volume 19. Number 5/6, 2001b, pp. 204 -214, MCB University Press.

[24] De Wolf, C., F. Pomponi, A. Moncaster "Measuring embodied carbon dioxide equivalent of buildings: A review and critique of current industry practice", Energy and Buildings 140: 2017, 68-80.

[25] Nitu, I. F., T. Catalina "Analysis of the thermal and acoustic comfort of BREEAM certified office building", Acta Technica Napocensis:Civil Engineering and Architecture Vol. 61 (2), 2018, $21-29$.

[26] Akintayo, F. O., ON. Oyebade, SP. Songca, NO. Adebisi, OS. Oluwafemi, OO. Fadipe "Assessment of the impacts of building construction activities on the environment", Nigerian Journal of Technology, Vol. 39 (2), 2020, 325 - 331.

[27] Ciravoglu, A. "A research on embodied energy of building materials: reflections on turkey", The 2005 World Sustainable Building
Conference, Tokyo, 27-29 September 2005, 01-131 (SB05Tokyo), pp 910 - 917.

[28] Alade, K.T., A. N. Oyebade and N.U. Nzewi "Assessment of the Use of Locally Available Materials for Building Construction in Ado-Ekiti Nigeria", Journal of Construction Business and Management 2 (2), 2018, 36-41 37.

[29] Don C. I. Okpala "Promoting the use of local building materials in Nigerian house construction: Problems and prospects. Ekistics, 1983, Vol. 50, January/February, No. 298, Housing In Neighborhoods (January/February), 1983, pp. 42-46.

[30] Omole, F. K., and Bako, A. I. "Analysis of the Problems and Prospects in the Use of Local Building Materials: Review of Literature", Analysis, 3(11), 2013, 2-5 .

[31] Oloruntoba K. and Ayodele E.O "(2013) Local Building Materials: a Tool Towards Effective Low-Income Housing in Nigeria", Middle-East Journal of Scientific Research 18 (4):, 2013, 492-497.

[32] Ikechukwu O. and Iwuagwu B.U. "2016 Traditional Building Materials as a Sustainable Resource and Material for Low Cost Housing in Nigeria: Advantages, Challenges and the Way Forward", Int'l Journal of Research in Chemical, Metallurgical and Civil Engg. (IJRCMCE) Vol. 3, Issue 2 2016, 247 - 252

[33] Bardhan, S. "Embodied energy analysis of multi storied residential buildings in urban India. Energy and Sustainability III, WIT Transactions on Ecology and the Environment, Vol 143, 2011 WIT Press.

[34] Ononiwu, N. H., S. C. Nwanya "Embodied Energy and Carbon footprints in Residential buildings", International Journal of Advanced Engineering Research and Science (IJAERS), Vol-3 (8), 2016, 49 -54

[35] Prucnal-Ogunsote, B., "Classification of Nigerian Architecture", AARCHES Journal, 1(6), 2001, pp.48-56.

[36] Oladiran, O. J. "Investigating the Use of Local Materials for Building Construction", Journal of Sustainable Technology, Vol. 6, No. 2 (November), 2015.

[37]Ede, A.N., Adebayo, S.O., Bamigboye, G.O. and Ogundeji, J., "Structural, economic and environmental study of concrete and timber as structural members for residential buildings in Nigeria", The International Journal of Engineering and Science, 4(3), 2015, pp.76-84.

[38] Fasogbon, S. K., A. B. Wahaab, M. O. Oyewola "Thermal comfort characteristics of some selected building materials in the regional 
setting of Ile-Ife, Nigeria", Journal of Natural Resources \& Development. 5, 2015, 54 - 58.

[39] Balounova, M., F. Greco, K. Kabele, P. kabele "Use of building performance simulation for structural analysis of historical building", Proc. BS2015, $14^{\text {th }}$ Conf. Int. Building Performance Simulation Association, Hyderabad, India, Dec. 2015, 7-9.

[40] Prasanthi R., V. Svetlana, J. O. Raymond and R. I. Jimmie Hinze "University of Florida Proceedings of the 2011 Winter Simulation Conference, S. Jain, R.R. Creasey, J. Himmelspach, K.P. White, and M. Fu, eds., 2011.

[41] Abisuga, A.O. and O.O. Oyekanmi "Organizational Factors Affecting the Usage of Sustainable Building Materials in the Nigerian Construction Industry", Journal of Emerging Trends in Economics and Management Sciences 5(2): 2014, 113-119.

[42] Onyegiri, I. and I. B. Ugochukwu "Traditional building materials as a sustainable resource material for low cost housing in Nigeria: advantages, challenges and the way forward", Int'l Journal of Research in Chemical, Metallurgical and Civil Engg. Vol. 3, Issue 2, 2016, pp247-252.

[43] Obia, A. E., E. B. Itam, A. E. Archibong, D. A. Uyanah, E. A. Obia "Sustainable Architecture: Bamboo in Contemporary Building Construction in South-South Nigeria", International Journal of Architecture, Engineering and Construction, Vol. 5, No 3, (September), 2016, 1 - 12.

[44] Ameh, J. A., A. Soyingbe, O. Oyediran "Acceptability and use of innovative bamboo products for the construction of residential buildings in Nigeria", International Journal of Technology, 10 (4): 2019, 648 -656.

[45] Adedeji, Y. M. D. "Sustainable Housing Provision: Preference for the Use of Interlocking Masonry in Housing Delivery in Nigeria", Architecture Research 2(5): 2012, 81-86.

[46] Ohagwu, C. J. and B. O. Ugwuishiwu "Status of wood processing and storage in Nigeria", Nigerian Journal of Technology, Vol. 30 (2), 2011, 96 - 104.

[47] Ojo, I. C "Development of building materials towards effective housing in Nigeria", Nigerian Journal of Engineering Management, Vol 12 (1), 2011, $20-25$.
[48] Obia, Ajah Ekpeni "Emerging Nigerian Megacities and Sustainable Development: Case Study of Lagos and Abuja", Journal of Sustainable Development, Vol. 9, No. 2; 2016, pp27 -42.

[49] Edwards, B. "Sustainable architecture: European directives and building design", Butterworth Architecture, 1999.

[50] Akbarnezhad, A. and J. Xiao "Estimation and Minimization of Embodied Carbon of Buildings: A Review", Buildings 7 (5) 2017, 1- 24.

[51] Joseph, P., S. Tretsiakova-McNally "Sustainable Non-Metallic Building Materials", Sustainability 2, 2010, 400-427.

[52] Gupta, M. S. "Strawbale construction - a least embodied energy material", International Journal of Civil, Structural, Environmental and Infrastructure Engineering Research and Development, 2249-7978 Vol. 9, 2019, (2), 1-6

[53] Korhonen, J., T. P. Seager "Beyond ecoefficiency: a resilience perspective", Business strategy and the environment $\mathrm{Vol}$ 17, 2008, 411 $-419$.

[54] Jalam, U. A., A. A. Jalam, I. M. Sale, O. F. Job "Cost Evaluation of Utilising Building Materials Derived from Agricultural Waste as Sustainable Materials for Lightweight Construction", Economic and Environmental Studies Vol. 16, No. 4 (40/2016), December 2016, 673-685.

[55] Baiden, B. K., K. Agyekum,J. K. Ofori-Kuragu "Perceptions on Barriers to the Use of Burnt Clay Bricks for Housing Construction", Journal of Construction Engineering, Volume 2014, pp. 1- 7.

[56] Oluigbo, S. N., A. C. Odoh "Technological Capabilities and Sustainable Housing Delivery: Case Studies from Nigeria", Journal of Environment and Earth Science, Vol.6, No.6, 2016, pp. 76-82.

[57] Chen, J., W. Zhou, H. Yang "Is Embodied Energy a Better Starting Point for Solving Energy Security Issues?-Based on an Overview of Embodied Energy-Related Research", Sustainability 2019, 11, 4260.

[58] Costanza, R. "Embodied Energy and Economic Valuation", Science, 210, 1980, 1219-1224.

[59] Lenzen, M. "Primary energy and greenhouse gases embodied in Australian final consumption: An input-output analysis", Energy Policy 26, 1998, 495-506. 